\title{
A heterogeneous model of disposition effect
}

\author{
Mao-Wei Hung* and Hsiao-Yuan Yu \\ College of Management, National Taiwan University, No. 1, Section 4, \\ Roosevelt Road, Taipei, Taiwan
}

A portfolio choice model is provided to illustrate the disposition effect under irrational belief in mean reversion assumption. Higher cognitive reference, stronger irrational belief in mean reversion magnitude and less risk aversion all strengthen the disposition effect in the model. The equilibrium market interest rate is priced after the market clearing condition is employed. The grater disposition effect reduces the capital mobility from the stock market to the bond market and thus mitigates the dropping of the market interest rate.

\section{Introduction}

Investors sometimes are reluctant to realize their capital losses as paper losses occurred but are willing to realize their capital gains as paper gains occurred. This asymmetric financial behaviour is termed as the 'Disposition Effect' by Shefrin and Statman (1985). Many different theories and researches have been proposed to explain it. However, to the best of the authors' knowledge, most disposition effect related papers are empirical researches and studies. Pure theoretical models are still scarce in this field. Thus, the motivation is to construct a theoretical model on the disposition effect in this paper. Based on previous literature, the most prevalent theory is the prospect theory, provided by Kahneman and Tversky (1979). However, in Odean (1998, p. 1777), ${ }^{1}$ an alternative behaviour theory - the irrational belief in mean reversion - is introduced:

Investors might choose to hold their losers and sell their winners not because they are reluctant to realize losses but because they believe that today's losers will soon outperform today's winners... If, however future expected returns for losers are not greater than those for winners, but investors continue to believe they are despite persistent evidence to the contrary, this belief would be irrational... Most of the analysis presented here does not distinguish between prospect theory and an irrational belief in mean reversion as possible explanations for why investors hold losers and sell winners...

Based on Odean (1998), and Barberis and Thaler (2002), a disposition effect related theoretical model is built in this paper that is based upon the irrational belief in mean reversion. This is motivated by how financial economists construct their theoretical models for the disposition effect based on the prospect theory; only few or even none put emphasis on irrational belief in mean reversion so far. Therefore, the main goal is to try to build a simple theoretical model based on irrational belief in mean reversion for better interpretation of the disposition effect. In addition to the mean reversion belief, the concept of cognitive reference price level from Grinblatt and Han (2001), and Odean (1998) is also employed into the setup of the mean reversion process. This

*Corresponding author. E-mail: hung@mba.ntu.edu.tw

${ }^{1}$ Barberis and Thaler (2002) surveyed the irrational belief in mean reversion theory. 
helps investors judge whether they have cognitive paper losses or gains. Besides, similar to Dumas (1989), and Kogan and Uppal (2000, 2002), ${ }^{2}$ heterogeneous agents are incorporated into the economy. This completes the model and brings about various dynamic results.

There are still some distinctions in this paper amongst other previous papers and caveats worth mentioning. First, in contrast with Grinblatt and Han (2001), the cognitive reference price level and the current stock price are added into the equity premium term instead of into the market demand term. This is because the focus is the portfolio choice and the disposition effect, not the market returns. Second, after modelling the theory of irrational belief in mean reversion, it is possible to setup cognitive reference price level and current stock price in the form of mean reversion. ${ }^{3}$ Note that when the current stock price is above the investor's cognitive reference price level (in gain domains), investors accrue paper gains and the mean reversion belief fails to work. Consequently, there is no (negligible) disposition effect. However, when the current stock price falls below the investor's cognitive reference price level (in loss domains), investors suffer paper losses and the mean reversion belief starts to work; hence generates a disposition phenomenon. This phenomenon could be traced back to the concept of mean reversion. A belief that falling into the loss domains convinces investors to believe that current falling stock price is temporary and prices will recover soon. This belief indeed makes investors reluctant immediately to realize their losses. Third, similar to Dumas (1989), and Kogan and Uppal (2000, 2002), the aggregate wealth share is used as the state variable. This provides various asset pricing implications in the equilibrium. However, in contrast with them, the analytical solutions are approximated using the log linearization approach provided by Campbell and Viceira (2002), not the perturbation analysis approach by Kogan and Uppal (2000, 2002). Besides, due to choosing the aggregate wealth share as the state variable, a second power and second power interaction term of market interest rate and aggregate wealth share are employed to solve the model and to apply the log linearization approach. This is different from Vasicek (1977) who chooses the market interest rate as the state variable and distinct from Campbell and Viceira (2002) who uses the first power log linearization approximation.

Prior disposition effect related papers were mostly empirical studies. Andreassen (1988) demonstrates that individuals make their buying and selling decisions as if they expect short-term mean reversion. Czarnitzk and Stadtmann (2005) reports a positive relation between the sales of investor magazines and the stock market development to elucidate disposition effect. Odean (1999), Barber and Odean (2002) and Barber et al. (2003) provide empirical evidence that buying decision, due to the searching problem, virtually depends on the attention effect and implies that the irrational belief in mean reversion may have little impact on the buying decision. As to the selling decisions, Odean (1998) successfully uses empirical data to elucidate supportive evidence of the disposition effect. ${ }^{4,5}$ In Odean (1998), both prospect theory and irrational belief in mean reversion are main candidates for explaining the disposition effect. It suggests that the irrational belief in mean reversion plays a key role in the selling decision and in the phenomenon of disposition effect. In addition to the prospect theory and the irrational belief in mean reversion, Lakonishok and Smidt (1986) provide some other reasons for the disposition effect, the purpose of diversification of market portfolio and the realization of private favourite information. Harris (1988) highlights expensive trading costs of lower price stocks to explain the disposition effect.

Disposition effect is found not only in stock markets but also in other asset markets. ${ }^{6}$ Genesove and Mayer (2001) find that in the housing markets, sellers are usually reluctant to sell their house below their original purchase price. In the futures markets, Coval and Shumway (2000) present the behavioural study of professional traders in the

\footnotetext{
${ }^{2}$ Wang (1996) and Detemple and Murthy (1997) also provide heterogeneous agents and portfolio constraint models. Campbell (2000) surveys the heterogeneity in asset pricing at the millennium. Affuso (2002) and Holman and Graves (2002) empirically report the significant importance of heterogeneity by UK and US data respectively.

${ }^{3}$ Arak and Taylor (1996) have developed and tested the mean-reverting model setup between foreign stocks and closed-end country funds.

${ }^{4}$ Grinblatt and Keloharju (2001) have the similar empirical disposition effect results by using Finland data. They find that past returns have important influence in determining disposition behaviour and the seasonality plays another interesting issue as well.

${ }^{5}$ Shapira and Venezia (2001) report some similar disposition results by using Israeli data. They show that not only the individual investors have the disposition effect but also do the institutional investors.

${ }^{6}$ Dyl (1977), Constantinides (1984), Lakonishok and Smidt (1986), and Badrinath and Lewellen (1991) all provide evidence of disposition effect.
} 
Treasury Bond futures pit at the CBOT. ${ }^{7}$ In their study, the traders who have earned profits in the morning tend to take less risk in the afternoon, while the traders who have accumulated losses in the morning are willing to take more risk in the afternoon. This is consistent with the disposition effect explained by the prospect theory.

This paper emphasizes two main contributions which include: (1) building a simple pure theoretical model for disposition effect based on irrational belief in mean reversion and (2) successfully comparing two heterogeneous agents' portfolio choices and pricing the equilibrium market interest rate. It is organized as follows: Section II introduces the disposition effect model with irrational belief in mean reversion. Optimal consumption and portfolio choice policies are eventually derived for heterogeneous agents in this section. Market clearing condition to solve the equilibrium interest rate is included in this section as well. Section III applies the results from the previous sections and discusses their portfolio applications and asset pricing implications. Some implication calibrations are given in Section IV. Finally, Section V concludes the paper.

\section{The Disposition Effect Model}

Following Dumas (1989), Odean (1998), Kogan and Uppal (2000), Grinblatt and Han (2001), Campbell and Viceira (2002), Chang and Hung (2002), and Wirjanto (2004), a fundamental consumption-based theoretical model is provided to elucidate the disposition effect in the asset market.

\section{Investment opportunity set and economy}

It is assumed that there are only two different assets in the chosen economy. One is the risk-free asset in the bond market and the other is the risky asset in the stock market. The aggregate wealth share is selected as the state variable and adopt the power utility over consumption with different constant relative risk aversion for two heterogeneous investors. The model is as follows:

For type I agent who is the disposition investor:

$$
\begin{gathered}
\mathrm{U}\left(C_{1}\right) \frac{C_{1}^{1-\gamma_{1}}}{1-\gamma_{1}} \\
\frac{\mathrm{d} P_{t}}{P_{t}}=\left[\mu+\lambda_{1}\left(1-\frac{P_{t}}{R_{t}}\right)\right] \mathrm{d} t+\sigma \mathrm{d} Z
\end{gathered}
$$

For type II agent who is the rational investor:

$$
\begin{gathered}
\mathrm{U}\left(C_{2}\right)=\frac{C_{2}^{1-\gamma_{2}}}{1-\gamma_{2}} \\
\frac{\mathrm{d} P_{t}}{P_{t}}=\mu \mathrm{d} t+\delta \mathrm{d} Z
\end{gathered}
$$

and for both agents:

$$
\begin{gathered}
\frac{\mathrm{d} B_{t}}{B_{t}}=r_{t} \mathrm{~d} t \\
\mathrm{~d} s=\bar{\kappa}(\bar{s}-s) \mathrm{d} t+\sigma_{s} \mathrm{~d} Z_{s}
\end{gathered}
$$

where $s=W_{1} /\left(W_{1}+W_{2}\right)$ and subscripts denote the types.

Equations 1 and 2 are for the disposition investor while Equations 3 and 4 are for the rational investor. Two agents are set to be heterogeneous not only in preference but also in expected price dynamics (in beliefs) outset. Equations 5 and 6 are the same for both agents. In Equations 1 and 3, the power utility over consumption with different constant relative risk aversion, $\gamma_{1}$ and $\gamma_{2}$ are for the disposition investor and for the rational investor, respectively. In terms of the rational investor, the risky asset evolves according to Equation 4 which follows a geometric Brownian motion; where the diffusion term, $\sigma$, presents the instantaneous volatility of the risky asset and the drift term, $\mu$ presents the instantaneous return of the risky asset. In contrast to the rational investor, the disposition investor measures (believes) the evolution of risky asset according to Equation 2, which is almost the same as Equation 4 with the exception of the drift term. In the drift term of Equation 2, besides the constant return $\mu$, there is one other excess premium component, $\lambda_{1}\left(1-\left(P_{t} / R_{t}\right)\right)$; where $\lambda_{1} \geq 0$, and $P_{t}, R_{t}$ present the current risky asset price and the cognitive reference price level, respectively $P_{t}$ varies with the stock price while $R_{t}$ is fixed initially by the disposition investor. The reference level $\left(R_{t}\right)$ could be thought of as investor's original purchase cost. The term $\lambda_{1}\left(1-\left(P_{t} / R_{t}\right)\right)$, referred to as the irrational belief in mean reversion, is set in the form of mean reversion because it will help generate the disposition effect. The rational investor has no concept of the cognitive reference price level and has no irrational belief in mean reversion. Thus she would not expect the extra premium. On the contrary, the disposition investor is knowledgeable of cognitive reference price level and irrational belief in mean reversion. Consequently she expects to generate the extra premium when choosing a risky asset. This is the

\footnotetext{
${ }^{7}$ Locke and Mann (1999) provide the professional futures traders have tendency to hold losing trades with longer periods and larger positions than to hold winning trades.
} 
discrepancy between the rational investor and the disposition investor. If the current price is below the cognitive reference price level, a disposition investor with the extra premium will raise her total required equity premium since $\lambda_{1}\left(1-\left(P_{t} / R_{t}\right)\right)>0$. In the following sections, it is demonstrated that higher required equity premium indeed creates the disposition effect. Equation 5 states the dynamic process of the risk-free asset with the instantaneous drift term $r$. The state variable, the aggregate wealth share, is defined as the proportion of the disposition investors' wealth over aggregate wealth. In Equation 6, it is assumed that the aggregate wealth share follows an Ornstein-Uhlenbeck process; where $\bar{\kappa} \in(0,1)$ presents the adjustment speed; $\bar{s}$ presents the long run mean and $\sigma_{s}$ is the instantaneous volatility of the aggregate wealth share. Finally, both $Z$ and $Z_{s}$ are standard Wiener processes and where $\mathrm{d} Z_{s} \mathrm{~d} Z=\rho \mathrm{d} t$ and $\rho$ is the correlation coefficient between $Z$ and $Z_{s}$.

\section{The optimal consumption policies and portfolio choices}

An imaginary social planner is used to demonstrate the maximization problem of the whole economy. In this economy, the planner wants to maximize the following inter-temporal expected welfare utility and is subject to the inter-temporal budget constraint.

$\max _{\left\{C_{1}, C_{2}, \alpha_{1}, \alpha_{2}\right\}} \mathrm{E}_{0}\left\{\int_{0}^{\infty} \mathrm{e}^{-\beta t}\left[\theta \frac{C_{1}^{1-\gamma_{1}}}{1-\gamma_{1}}+(1-\theta) \frac{C_{2}^{1-\gamma_{2}}}{1-\gamma_{2}}\right] \mathrm{d} t\right\}$

subject to

$$
\begin{aligned}
\mathrm{d} W= & \mathrm{d}\left(W_{1}+W_{2}\right) \\
= & \left\{\left[\alpha_{1}\left(\mu+\lambda_{1}\left(1-\frac{P_{t}}{R_{t}}\right)-r_{t}\right)+r_{t}\right] W_{1}-C_{1}\right\} \mathrm{d} t \\
& +\alpha_{1} W_{1} \sigma \mathrm{d} Z+\left\{\left[\alpha_{2}\left(\mu-r_{t}\right)+r_{t}\right] W_{2}-C_{2}\right\} \mathrm{d} t \\
& +\alpha_{2} W_{2} \sigma \mathrm{d} Z
\end{aligned}
$$

where $C_{1}, C_{2}$ and $W_{1}, W_{2}$ present the consumption and the wealth of the disposition investor and of rational investor, respectively. $\mathrm{E}$ is the expectation operator. $\beta$ is the individual discount rate which is set to be constant over time. $\theta$ and $(1-\theta)$ are the planner's subjective weights (NOT the wealth weights) of the disposition investor and of the rational investor, respectively. Finally, $\alpha_{1}$ and $\alpha_{2}$ denote the portfolio choices invested in the risky asset of the disposition investor and of the rational investor, respectively.

Adopting the dynamic programming approach, there is the value function $\mathrm{J}\left(W_{1}, W_{2}, r_{t}, s, t\right)$ that satisfies suitable regularities and the transversality condition: $\quad \lim _{t \rightarrow \infty} \mathrm{E}_{0}\left[\mathrm{~J}\left(W_{1}, W_{2}, r_{t}, s, t\right)\right]=0 . \quad$ Thus there is the following Euler equations that suggest the optimal consumptions and portfolio choices.

$$
\begin{aligned}
& \mathrm{U}_{\mathrm{C}_{1}}=\theta \mathrm{e}^{-\beta t} C_{1}^{-\gamma_{1}}=\mathbf{J}_{W_{1}} \\
& \mathrm{U}_{\mathrm{C}_{2}}=(1-\theta) \mathrm{e}^{-\beta t} C_{2}^{-\gamma_{2}}=\mathbf{J}_{W_{2}} \\
& \alpha_{1}=\left[1-\frac{\left(\mathbf{J}_{W_{1} W_{2}}\right)^{2}}{\left(\mathbf{J}_{W_{1} W_{1}} W_{1}\right)\left(\mathbf{J}_{W_{2} W_{2}} W_{2}\right)}\right]^{-1} \\
& \times\left\{\left[\frac{1}{-\mathbf{J}_{W_{1} W_{1}} W_{1} / \mathbf{J}_{W_{1}}}+\frac{\left(\mathbf{J}_{W_{1} W_{2}}\right)\left(\mathbf{J}_{W_{2}}\right)}{\left(\mathbf{J}_{W_{1} W_{1}} W_{1}\right)\left(\mathbf{J}_{W_{2} W_{2}} W_{2}\right)}\right.\right. \\
& \left.\times\left(\frac{W_{2}}{W_{1}}\right)\right] \frac{\mu-r}{\sigma^{2}}+\left[\frac{1}{-\mathrm{J}_{W_{1} W_{1}} W_{1} / J_{W_{1}}} \frac{\lambda_{1}(1-(P / R))}{\sigma^{2}}\right] \\
& \left.+\left[\frac{-\mathbf{J}_{W_{1} s}}{\mathbf{J}_{W_{1} W_{1} W_{1}}}+\frac{\left(\mathbf{J}_{W_{1} W_{2}}\right)\left(\mathbf{J}_{W_{2} s}\right)}{\left(\mathbf{J}_{W_{1} W_{1}} W_{1}\right)\left(\mathbf{J}_{W_{2} W_{2}} W_{2}\right)}\right] \frac{\sigma_{s}}{\sigma} \rho\right\} \\
& =\alpha_{1}^{M}+\alpha_{1}^{I B}+\alpha_{1}^{H} \\
& \alpha_{2}=\left[1-\frac{\left(\mathbf{J}_{W_{1} W_{2}}\right)^{2}}{\left(\mathbf{J}_{W_{1} W_{1}} W_{1}\right)\left(\mathbf{J}_{W_{2} W_{2}} W_{2}\right)}\right]^{-1} \\
& \times\left\{\left[\frac{1}{-\mathbf{J}_{W_{2} W_{2}} W_{2} / \mathbf{J}_{W_{2}}}+\frac{\left(\mathbf{J}_{W_{1} W_{2}}\right)\left(\mathbf{J}_{W_{1}}\right)}{\left(\mathbf{J}_{W_{1} W_{1}} W_{1}\right)\left(\mathbf{J}_{W_{2} W_{2}} W_{2}\right)}\right.\right. \\
& \left.\times\left(\frac{W_{1}}{W_{2}}\right)\right] \frac{\mu-r}{\sigma^{2}}+\left[\frac{\left(\mathrm{J}_{W_{1} W_{2}}\right)\left(\mathrm{J}_{W_{1}}\right)}{\left(\mathrm{J}_{W_{1} W_{1}} W_{1}\right)\left(J_{W_{2} W_{2}} W_{2}\right)}\left(\frac{W_{1}^{*}}{W_{2}}\right)\right. \\
& \times \frac{\lambda_{1}(1-(P / R))}{\sigma^{2}} \\
& \left.+\left[\frac{-\mathbf{J}_{W_{2} s}}{\mathbf{J}_{W_{2} W_{2}} W_{2}}+\frac{\left(\mathbf{J}_{W_{1} W_{2}}\right)\left(\mathbf{J}_{W_{1} s}\right)}{\left(\mathbf{J}_{W_{1} W_{1}} W_{1}\right)\left(\mathbf{J}_{W_{2} W_{2}} W_{2}\right)}\right] \frac{\sigma_{s}}{\sigma} \rho\right\} \\
& =\alpha_{2}^{M}+\alpha_{2}^{I B}+\alpha_{2}^{H}
\end{aligned}
$$

where the subscripts of value function $\mathbf{J}$ denote the partial derivatives.

Equations 9 and 10 are referred to as the envelope condition' which states that the optimal consumption policy depends on the marginal value function. Different from traditional envelope conditions, the optimal consumption policies depend not only on the value function but also on the social planner's subjective weights.

In Equation 11, the optimal portfolio choice for the disposition investor consists of three main parts: the myopic demand $\left(\alpha_{1}^{M}\right)$, the irrational belief demand $\left(\alpha_{1}^{I B}\right)$, and the hedging demand $\left(\alpha_{1}^{H}\right)$. The first term on the right hand side in Equation 11 is referred to as the myopic demand, which measures the effect of excess return on the portfolio choice. It comprises both type of agents' effects $\left(\mathbf{J}_{W_{1} W_{1}}\right.$ and $\left.\mathbf{J}_{W_{2} W_{2}}\right)$, the interaction effect $\left(\mathbf{J}_{W_{1} W_{2}}\right)$, and the wealth ratio $\left(W_{2} / W_{1}\right)$ between the rational investor and the disposition investor. The interaction effect and the wealth ratio effect are rarely studied in previous literature. Note that the $\left(-\mathbf{J}_{W_{1} W_{1}} W_{1} / \mathbf{J}_{W_{1}}\right)$ is referred to as the Arrow-Pratt 
measure of risk aversion. The middle part on the right hand side in Equation 11 is termed as the irrational belief demand which is the main focus in this paper. As to the disposition investor's part, it is very similar to the prior myopic demand. Both of them include risk premiums and are measured by the risk aversion of the disposition investor and by the instantaneous volatility of risky assets. The differences between the two are the forms of required risk premiums. The myopic demand requires an excess return premium $(\mu-r)$ yet the irrational belief demand requires a mean reverting risk premium $\left(\lambda_{1}\left(1-\left(P_{t} / R_{t}\right)\right)\right)$ which is dependent upon the current risky asset price and the disposition investor's cognitive reference price level. At last, the rest of the right-hand side in Equation 11 is referred to as the hedging demand. Disposition investor adopts the aggregate wealth share to be the state variable as her hedging tools. It also incorporates both type of agents' effects and the interaction effect between them. As to the rational investor's optimal portfolio choice in Equation 12, it is similar to the prior disposition investor's portfolio choice. Nevertheless, the main discrepancy between Equation 11 and Equation 12 is the middle term, the irrational belief demand. When observing the irrational belief demand of the rational investor and of the disposition investor, it is obvious that the disposition investor governs her irrational belief demand by the risk aversion, $\left(-\mathbf{J}_{W_{1} W_{1}} W_{1} / \mathbf{J}_{W_{1}}\right)$, but the rational investor governs her irrational belief demand through the interaction effect and the relative wealth ratio. This great distinction certainly brings a total different story to our paper. This distinction will be reviewed in the coming sections.

\section{Analytical solutions of Heterogeneous investors}

Following Campbell and Viceira (2002) and Chang and Hung (2002), it is known that the optimal consumption policies and portfolio choices for each investor are: ${ }^{8}$

$$
\begin{aligned}
& c_{1}-w_{1}=-\left(a_{0}+a_{1} s+a_{2} s^{2}+a_{3} r+a_{4} r^{2}+a_{5} r s\right) \\
&+\frac{1}{\gamma_{1}} \log \theta \\
& c_{2}-w_{2}=-\left(b_{0}+b_{1} s+b_{2} s^{2}+b_{3} r+b_{4} r^{2}+b_{5} r s\right) \\
&+\frac{1}{\gamma_{2}} \log (1-\theta) \\
& \alpha_{1}=\frac{1}{\gamma_{1}} \frac{(\mu-r)}{\sigma^{2}}+\frac{1}{\gamma_{1}} \frac{\lambda_{1}(1-(P / R))}{\sigma^{2}}+\left(\frac{2 A_{2}-A_{0} \phi_{1}}{2 A_{2}\left(A_{1}+A_{4}\right)}\right) \\
& \times\left[\frac{\sigma_{s}}{\sigma} \rho r+A_{2}(s-\bar{s})-A_{3}\right] \frac{\sigma_{s}}{\sigma} \rho \\
&=\alpha_{1}^{M}+\alpha_{1}^{I B}+\alpha_{1}^{H} \\
& \alpha_{2}=\frac{1}{\gamma_{2}} \frac{(\mu-r)}{\sigma^{2}}+\left(\frac{2 B_{2}-B_{0} \psi_{1}}{2 B_{2}\left(B_{1}+B_{4}\right)}\right) \\
& \times\left[\frac{\sigma_{s}}{\sigma} \rho r+B_{2}(s-\bar{s})-B_{3}\right] \frac{\sigma_{s}}{\sigma} \rho \\
&=\alpha_{2}^{M}+\alpha_{2}^{H}
\end{aligned}
$$

where

$$
\begin{aligned}
& a_{0}=\left(A_{0} \phi_{1}\right)^{-1}\left\{A_{0}\left(\phi_{0}+\frac{\phi_{1} \log \theta}{\gamma_{1}}\right)-\frac{\left.\left[\mu+\lambda_{1}\right)(1-(P / R))\right]^{2}}{2 \gamma_{1} \sigma^{2}}+\frac{\beta}{1-\gamma_{1}}+\frac{2 A_{2}-A_{0} \phi_{1}}{2 A_{2}\left(A_{1}+A_{4}\right)}\left[\left(A_{2} \bar{s}+A_{3}\right)^{2}\left(\frac{A_{0} \phi_{1}}{2 A_{2}}\right)-A_{2} A_{4}\right]\right\} \\
& a_{1}=\frac{\left(2 A_{2}-A_{0} \phi_{1}\right)}{2 A_{2}\left(A_{1}+A_{4}\right)}\left(-A_{2} \bar{s}-A_{3}\right) \\
& a_{2}=\frac{2 A_{2}-A_{0} \phi_{1}}{4\left(A_{1}+A_{4}\right)} \\
& a_{3}=\left(-A_{0} \phi_{1}\right)^{-1}\left\{\left[1-\frac{\mu+\lambda_{1}(1-(P / R))}{\gamma_{1} \sigma^{2}}\right]+\left(\frac{\sigma_{s}}{\sigma} \rho\right)\left(\frac{2 A_{2}-A_{0} \phi_{1}}{2 A_{2}\left(A_{1}+A_{4}\right)}\right)\left(A_{2} \bar{s}+A_{3}\right)\left(\frac{A_{0} \phi_{1}}{A_{2}}\right)\right\} \\
& a_{4}=\left(-A_{0} \phi_{1}\right)^{-1}\left[\frac{1}{2 \gamma_{1} \sigma^{2}}-\left(\frac{\sigma_{s}}{\sigma} \rho\right)^{2}\left(\frac{2 A_{2}-A_{0} \phi_{1}}{2 A_{2}\left(A_{1}+A_{4}\right)}\right)\left(\frac{A_{0} \phi_{1}}{2 A_{2}}\right)\right] \\
& a_{5}=\frac{2 A_{2}-A_{0} \phi_{1}}{2 A_{2}\left(A_{1}+A_{4}\right)} \frac{\sigma_{s}}{\sigma} \rho \\
& b_{0}=\left(B_{0} \psi_{1}\right)^{-1}\left\{B_{0}\left[\psi_{0}+\frac{\psi_{1} \log (1-\theta)}{\gamma_{2}}\right]-\frac{\mu^{2}}{2 \gamma_{2} \sigma^{2}}+\frac{\beta}{1-\gamma_{2}}+\left(\frac{2 B_{2}-B_{0} \psi}{2 B_{2}\left(B_{1}+B_{4}\right)}\right)\left[\left(B_{2} \bar{s}+B_{3}\right)^{2}\left(\frac{B_{0} \psi_{1}}{2 B_{2}}\right)-B_{2} B_{4}\right]\right\} \\
& b_{1}=\frac{\left(2 B_{2}-B_{0} \psi_{1}\right)}{2 B_{2}\left(B_{1}+B_{4}\right)}\left(-B_{2} \bar{s}-B_{3}\right)
\end{aligned}
$$

${ }^{8}$ The proof is available upon request. 


$$
\begin{aligned}
& b_{2}=\frac{2 B_{2}-B_{0} \psi_{1}}{4\left(B_{1}+B_{4}\right)} \\
& b_{3}=\left(-B_{0} \psi_{1}\right)^{-1}\left\{\left[1-\frac{\mu}{\gamma_{2} \sigma^{2}}\right]+\left(\frac{\sigma_{s}}{\sigma} \rho\right)\left(\frac{2 B_{2}-B_{0} \psi_{1}}{2 B_{2}\left(B_{1}+B_{4}\right)}\right)\left(B_{2} \bar{s}+B_{3}\right)\left(\frac{B_{0} \psi_{1}}{B_{2}}\right)\right\} \\
& b_{4}=\left(-B_{0} \psi_{1}\right)^{-1}\left[\frac{1}{2 \gamma_{2} \sigma^{2}}-\left(\frac{\sigma_{s}}{\sigma} \rho\right)^{2}\left(\frac{2 B_{2}-B_{0} \psi_{1}}{2 B_{2}\left(B_{1}+B_{4}\right)}\right)\left(\frac{B_{0} \psi_{1}}{2 B_{2}}\right)\right] \\
& b_{5}=\frac{2 B_{2}-B_{0} \psi_{1}}{2 B_{2}\left(B_{1}+B_{4}\right)} \frac{\sigma_{s}}{\sigma} \rho \\
& A_{0}=\frac{-\gamma_{1} \theta^{\left(1 / \gamma_{1}\right)}}{1-\gamma_{1}}, \quad A_{1}=\frac{\gamma_{1} \sigma_{s}^{2}\left(\rho^{2}-1\right)}{2}, \quad A_{2}=\frac{\gamma_{1} \bar{\kappa}}{1-\gamma_{1}}, \quad A_{3}=\frac{\sigma_{s}}{\sigma} \rho\left[\mu+\lambda_{1}\left(1-\frac{P}{R}\right)\right], \quad A_{4}=\frac{\gamma_{1} \sigma_{s}^{2}}{2\left(1-\gamma_{1}\right)} \\
& B_{0}=\frac{-\gamma_{2}(1-\theta)^{\left(1 / r_{2}\right)}}{1-\gamma_{2}}, \quad B_{1}=\frac{\gamma_{2} \sigma_{s}^{2}\left(\rho^{2}-1\right)}{2}, \quad B_{2}=\frac{\gamma_{2} \bar{\kappa}}{1-\gamma_{2}}, \quad B_{3}=\frac{\sigma_{s}}{\sigma} \rho \mu, \quad B_{4}=\frac{\gamma_{2} \sigma_{s}^{2}}{2\left(1-\gamma_{2}\right)} \\
& \phi_{0}=\mathrm{e}^{\overline{c_{1}-w_{1}}} \theta^{\left(-1 / \gamma_{1}\right)}\left[1-\overline{c_{1}-w_{1}}\right], \quad \phi_{1}=\theta^{\left(-1 / \gamma_{1}\right)} \mathrm{e}^{\overline{c_{1}-w_{1}}}, \\
& \psi_{0}=\mathrm{e}^{\overline{c_{2}-w_{2}}}(1-\theta)^{\left(-1 / \gamma_{2}\right)}\left[1-\overline{c_{2}-w_{2}}\right], \quad \psi_{1}=(1-\theta)^{\left(-1 / \gamma_{2}\right)} \mathrm{e}^{\overline{c_{2}-w_{2}}}
\end{aligned}
$$

The small letters of consumption and wealth present their corresponding log values.

Therefore, the social value function can be presented as:

$$
\begin{aligned}
\mathrm{J}\left(W_{1}, W_{2}, s, r, t\right)= & \mathrm{e}^{-\beta t+\gamma_{1}\left(a_{0}+a_{1} s+a_{2} s^{2}+a_{3} r+a_{4} r^{2}+a_{5} r s\right)} \frac{W_{1}^{1-\gamma_{1}}}{1-\gamma_{1}} \\
& +\mathrm{e}^{\beta t+\gamma_{2}\left(b_{0}+b_{1} s+b_{2} s^{2}+b_{3} r+b_{4} r^{2}+b_{5} r s\right)} \frac{W_{2}^{1-\gamma_{2}}}{1-\gamma_{2}}
\end{aligned}
$$

which is associated to a second power function with the state variable, the interest rate and the interaction term.

The optimal consumption policies for both agents are associated with the second power of the state

\section{Market clearing condition and equilibrium interest rate}

In the heterogeneous economy, the market interest rate is set as an endogenous variable left to be solved in the last. There are two asset markets in the model, the stock market and the bond market. Following Kogan and Uppal (2000), it is assumed, that the aggregate supply of stock is unity in the stock market and net zero supply of bond in the bond market. According to Walras' Law, the bond market is cleared to have the equilibrium interest rate. ${ }^{9}$

$$
s\left(1-\alpha_{1}\right)+(1-s)\left(1-\alpha_{2}\right)=0
$$

After the market clearing condition is employed, the equilibrium market interest rate is:

$r^{*}=\frac{1-\left(\mu / \gamma_{2} \sigma^{2}\right)-b_{5}\left[B_{2}(s-\bar{s})-B_{3}\right]-\left(s \lambda_{1}(1-(P / R)) / \gamma_{1} \sigma^{2}\right)+s\left[\left(\mu\left(\gamma_{1}-\gamma_{2}\right) / \gamma_{1} \gamma_{2} \sigma^{2}\right)-\left(a_{5} A_{2}-b_{5} B_{2}\right)(s-\bar{s})+\left(a_{5} A_{3}-b_{5} B_{3}\right)\right]}{\left(b_{5}\left(\sigma_{s} / \sigma\right) \rho-\left(1 / \gamma_{2} \sigma^{2}\right)\right)+s\left[\left(a_{5}-b_{5}\right)\left(\sigma_{s} / \sigma\right) \rho+\left(\gamma_{1}-\gamma_{2}\right) / \gamma_{1} \gamma_{2} \sigma^{2}\right]}$

variable, the market interest rate as well as their second power interaction term in the heterogeneous economy. The optimal portfolio choices for the two agents are associated with the first power of the state variable. The mean reversion belief $\left(\lambda_{1}(1-(P / R))\right)$ appears both in the irrational belief demand and in the hedging demand (in $A_{3}$ ) for agent I but totally disappears for agent II. This discrepancy helps generate the disposition effect phenomenon. This discrepancy in Section IV is calibrated.
Equation 17 demonstrates the equilibrium market interest rate in the heterogeneous economy. The irrational belief demand appearing in the numerator is ad hoc in this paper, thus conflicting with previous literatures.

\section{Asset Pricing Implications}

Some financial behavioural applications and asset pricing implications are introduced in this section.

${ }^{9}$ It is the same to clear the stock market: $s \alpha_{1}+(1-s) \alpha_{2}=1$. 


\section{Investment behaviours}

Based on the optimal portfolio policy in Equation 15, the disposition investor builds her portfolio choice according to the myopic demand, the irrational belief demand, and the hedging demand.

Recalling the irrational belief demand in Equation 15 , which has a mean reversion form that starts the asset allocation implications, the irrational belief demand is categorized into four specific investment behaviours. First, when the current stock price is above the individual's cognitive reference price level, it falls under the gain domains; on the other hand, when the current stock price is below the individual's cognitive reference price level, it falls under the loss domains. Whether the irrational belief demand works or not, Table 1 sorts out these four specific investment behaviours.

The rational investor. The rational makes her investment decisions based on the fundamental value that is reflected in the myopic demand $(\mu-r)$. In terms of the movement of stock prices, she does not have the mean reversion belief as an irrational believer. The irrational belief demand vanishes for the representative agent and thus makes here reduce to the rational investor.

$$
\begin{aligned}
\alpha_{1}(\text { Rational })= & \frac{1}{\gamma_{1}} \frac{(\mu-r)}{\sigma^{2}}+\left(\frac{2 A_{2}-A_{0} \phi_{1}}{2 A_{2}\left(A_{1}+A_{4}\right)}\right) \\
& \times\left[\frac{\sigma_{s}}{\sigma} \rho r+A_{2}(s-\bar{s})-A_{3}\right] \frac{\sigma_{s}}{\sigma} \rho \\
= & \alpha_{1}^{M}+\alpha_{1}^{H}
\end{aligned}
$$

The contrarian. The contrarian is faithful to the mean reversion belief in the mean reversion belief whenever the market price goes up or down. She treats irrational belief demand equally and symmetrically both in the gain and loss domains. Besides the basic myopic demand and the hedging demand, an agent who holds the irrational belief demand persistently is referred to as the contrarian.

$$
\begin{aligned}
\alpha_{1}(\text { Contrarian })= & \frac{1}{\gamma_{1}} \frac{(\mu-r)}{\sigma^{2}}+\frac{1}{\gamma_{1}} \frac{\lambda_{1}(1-(P / R))}{\sigma^{2}} \\
& +\left(\frac{2 A_{2}-A_{0} \phi_{1}}{2 A_{2}\left(A_{1}-A_{4}\right)}\right) \\
& \times\left[\frac{\sigma_{s}}{\sigma} \rho r+A_{2}(s-\bar{s})-A_{3}\right] \frac{\sigma_{s}}{\sigma} \rho \\
= & \alpha_{1}^{M}+\alpha_{1}^{I B}+\alpha_{1}^{H}
\end{aligned}
$$

The disposition investor. A disposition investor is influenced by the disposition effect, thus making her reluctant to sell losers. This peculiar behaviour occurs only when the underlying asset is a loser, not a winner. The investor waits for her portfolio price to come back to the original purchasing price or to her cognitive reference price because she has a belief in mean reversion when the price drops. This implies that the disposition investor treats the stocks in her portfolio unequally and asymmetrically. When the underlying asset market price is below her cognitive reference price, the asset is thus a loser. The disposition investor would consequently be reluctant to sell the asset. However, when the underlying asset market price is above her cognitive reference price, the asset would be a winner and the disposition investor would most likely behave rationally with regards to the fundamental value. The mean reversion belief to the irrational belief demand is employed here to elucidate the phenomenon of asymmetric behaviour. An agent holding the irrational belief demand when the market price is in the loss domains eventually evolves to a disposition investor in the economy. Her role switches back and forth from a rational investor to a contrarian. In the gain domains, she handles her portfolio based on the fundamental value and ignores the irrational belief demand; therefore she behaves like the rational investor. However, when she holds the irrational belief demand, she is reluctant to sell her losers and thus behaves similarly to the contrarian in the loss domains. Hence the disposition investor is regarded as a compound

Table 1. Four specific investment behaviours. According to different gain/loss domains and mean reversion belief (the irrational belief demand), the four specific investment behaviours are classified as follows.

\section{Gain domains}

Without mean reversion belief

With mean reversion belief

Loss domains

Without mean reversion belief With mean reversion belief

The rational investor The speculator
The disposition investor

The contrarian 
between the rational investor and the contrarian.

$$
\begin{aligned}
& \alpha_{1} \text { (Disposition) } \\
& =\left\{\begin{array}{l}
\frac{1}{\gamma_{1}} \frac{(\mu-r)}{\sigma^{2}}+\frac{1}{\gamma_{1}} \frac{\lambda_{1}(1-(P / R))}{\sigma^{2}}+\left(\frac{2 A_{2}-A_{0} \phi_{1}}{2 A_{2}\left(A_{1}+A_{4}\right)}\right) \\
\times\left[\frac{\sigma_{s}}{\sigma} \rho r+A_{2}(s-\bar{s})-A_{3}\right] \frac{\sigma_{s}}{\sigma} \rho \\
\frac{1}{\gamma_{1}} \frac{(\mu-r)}{\sigma^{2}}+\left(\frac{2 A_{2}-A_{0} \phi_{1}}{2 A_{2}\left(A_{1}+A_{4}\right)}\right) \\
\times\left[\frac{\sigma_{s}}{\sigma} \rho r+A_{2}(s-\bar{s})-A_{3}\right] \frac{\sigma_{s}}{\sigma} \rho
\end{array}\right. \\
& = \begin{cases}\alpha_{1}^{M}+\alpha_{1}^{I B}+\alpha_{1}^{H} & \text { if } P<R \\
\alpha_{1}^{M}+\alpha_{1}^{H} & \text { if } P \geq R\end{cases}
\end{aligned}
$$

The speculator. The last investment behaviour, the speculator, who behaves thoroughly opposite to the disposition investor, possesses an asymmetric perception toward the irrational belief demand. She is eager to pursue instantaneous profit and executes severe stop loss point in the market. This phenomenon could be explained by the asymmetric irrational belief demand as well. When the price goes up and reaches above her cognitive reference price, she fears a price drop and therefore sells her holdings arbitrarily. Nevertheless, when the price falls, rigorous stop loss point forces her no longer to wait for the price back and thus deal with the fundamental value. This implies that the irrational belief demand works for her in the gain domains only. An agent who holds the irrational belief demand in the gain domains eventually evolves to the speculator in the economy.

$$
\begin{aligned}
& \alpha_{1} \text { (Speculator) } \\
& =\left\{\begin{array}{c}
\frac{1}{\gamma_{1}} \frac{(\mu-r)}{\sigma^{2}}+\frac{1}{\gamma_{1}} \frac{\lambda_{1}(1-(P / R))}{\sigma^{2}}+\left(\frac{2 A_{2}-A_{0} \phi_{1}}{2 A_{2}\left(A_{1}+A_{4}\right)}\right) \\
\times\left[\frac{\sigma_{s}}{\sigma} \rho r+A_{2}(s-\bar{s})-A_{3}\right] \frac{\sigma_{s}}{\sigma} \rho \\
\frac{1}{\gamma_{1}} \frac{(\mu-r)}{\sigma^{2}}+\left(\frac{2 A_{2}-A_{0} \phi_{1}}{2 A_{2}\left(A_{1}+A_{4}\right)}\right) \\
\times\left[\frac{\sigma_{s}}{\sigma} \rho r+A_{2}(s-\bar{s})-A_{3}\right] \frac{\sigma_{s}}{\sigma} \rho
\end{array}\right. \\
& = \begin{cases}\alpha_{1}^{M}+\alpha_{1}^{I B}+\alpha_{1}^{H} & \text { if } P>R \\
\alpha_{1}^{M}+\alpha_{1}^{H} & \text { if } P \leq R\end{cases}
\end{aligned}
$$

The disposition effect and the market interest rate

Based on Equation 17, the equilibrium market interest rate in the heterogeneous economy is also affected by the irrational belief in mean reversion.
Table 2. Calibration parameters

\begin{tabular}{lcl}
\hline Parameters & Default value & Corresponding figures \\
\hline$\gamma_{1}$ & 2 & Fig. 2 $(1.1,2,10)$ \\
$\gamma_{2}$ & 4 & - \\
$\theta$ & 0.5 & - \\
$\mu$ & 0.06 & - \\
$\mathrm{r}$ & Endogenous & Fig. 4 \\
$\sigma^{2}$ & 0.4 & - \\
$\sigma_{s}^{2}$ & 0.4 & - \\
$\mathrm{e}^{\overline{c_{1}-w_{1}}}$ & 1 & - \\
$\mathrm{e}^{\overline{c_{2}-w_{2}}}$ & 1 & - \\
$\lambda_{1}$ & 0.6 & Fig. 4 $(0,0.6,1.2)$ \\
$\rho$ & 0.8 & - \\
$\bar{\kappa}$ & 1 & - \\
$\bar{s}$ & 0.5 & - \\
$s$ & $0.008-0.8$ & - \\
$\mathrm{P}$ & $\sim 100$ & Fig. 1, Fig. 3 \\
$\mathrm{R}$ & 50 & - \\
\hline
\end{tabular}

Notes: Parameters picked for calibration are presented. Different figures with different parameters are disclosed in the right most columns. The change of parameter value is presented in the parentheses.

The equilibrium interest rate is isolated from the irrational belief in mean reversion only if $\gamma_{1}=\left(a_{5} \sigma_{s} \sigma \rho\right)^{-1}$. But this outcome is not easily achievable. It is also not easy to directly judge the impact of irrational belief in mean reversion on the equilibrium market interest rate. However, it is intuitive that lower stock price usually brings hot money into the bond market and thus makes the interest rate decline. On the other hand, it is found that taking the disposition effect into consideration mitigates the dropping of market interest rate. This finding is verified in the coming calibration sections.

\section{Calibration}

Based on the previous model, some important results relating to the disposition effect are calibrated in this section. Note that due to lack of consistent and generally accepted measure of each variable, the focus will be on the relative magnitudes and influential directions, not their absolute values.

Table 2 summarizes all the related parameters picked for the calibration. The varieties of different variables and related figures are described on the corresponding right most columns.

$$
\frac{\partial r^{*}}{\partial\left(\lambda_{1}(1-(P / R))\right)}=\frac{s}{\left(b_{5}\left(\sigma_{s} / \sigma\right) \rho-\left(1 / \gamma_{2} \sigma^{2}\right)\right)+s\left[\left(a_{5}-b_{5}\right)\left(\sigma_{s} / \sigma\right) \rho+\left(\gamma_{1}-\gamma_{2}\right) /\left(\gamma_{1} \gamma_{2} \sigma^{2}\right)\right]}\left(a_{5}\left(\frac{\sigma_{s}}{\sigma}\right) \rho-\left(\frac{1}{\gamma_{1} \sigma^{2}}\right)\right)=0
$$




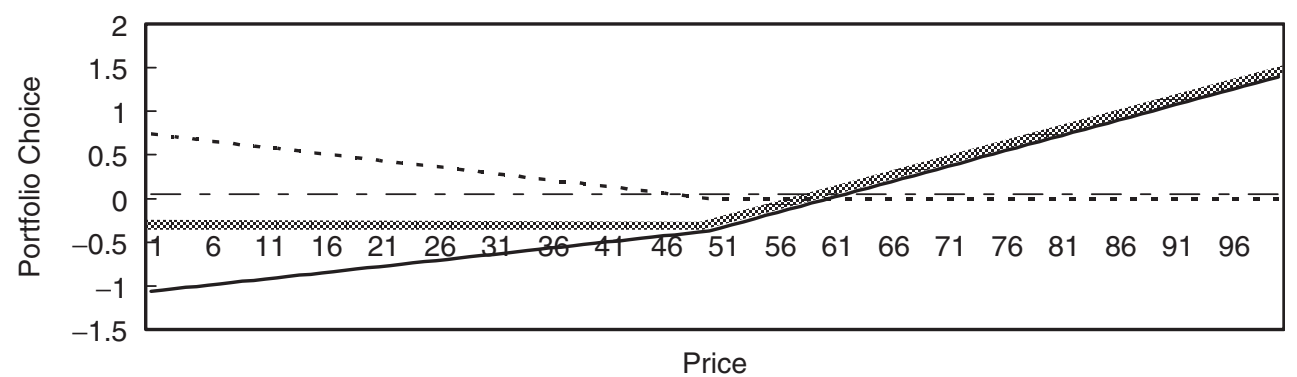

Fig. 1. Market price effect: Higher prices lead investors to allocate more weights on stocks due to the work of the state variable, aggregate wealth share. However, lower prices raise the portfolio weights as well because of the irrational belief in mean reversion. Note that the irrational belief demand works over loss domains only. The disposition effect from the irrational belief demand offsets the rational selling from the hedging demand and thus makes investors do not sell the losers eventually when facing losses. Alpha 1 sums the myopic demand and the irrational belief demand as well as the hedging demand: (- - -) myopic demand (- - - -) irrational belief demand, (-) hedging demand, (-) alpha 1.

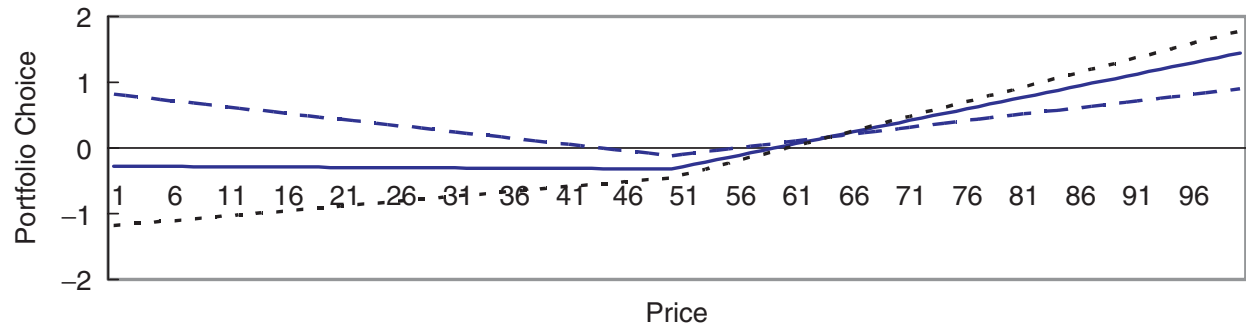

Fig. 2. Relative risk aversion effect: Investor gradually allocates more portfolio weight in risky assets while prices go up because of the hedging demand. However, conservative investor abandons holding risky assets while prices drop but by contrast, risktaking investor increasingly allocates more portfolio weight in holding risky assets. This makes less risk aversion investor behave more serious disposition effect over loss domain: $(---)$ gamma $1=1.1,(-)$ gamma $1=2,(----)$ gamma $1=10$.

\section{Market price effect}

Figure 1 describes the aggregate optimal portfolio choice which consists of three demands, the myopic demand, the irrational belief demand, and the hedging demand. The myopic demand is constant over time. The hedging demand increases the value of the portfolio as stock prices go up. The irrational belief demand works only over loss domains and elevates the portfolio choice. The raising from the irrational belief demand offsets the dropping from the hedging demand in the loss domains and thus the disposition effect makes investors not sell their losers when facing paper losses.

\section{Relative risk aversion effect}

The relative risk aversion coefficient governs the relative importance of each portfolio demand. The rationale behind an investor who gradually allocates more portfolio choice in a risky asset while prices increase could be traced to the concept of the hedging demand. In terms of the irrational belief demand, a conservative investor abandons holding risky assets while prices drop but by contrast a risk-taking investor increasingly allocates more portfolios in holding risky assets. This makes less risk aversion investor behave more serious disposition effect over loss domains. These results are verified in Fig. 2.

\section{Four specific Investment behaviours}

The irrational belief in mean reversion may work for different types of investors. For a rational investor, it fails to work over all price fields. For a contrarian, it works thoroughly and symmetrically over all domains. For a disposition investor, it works over loss domains only. As to a speculator, it works solely over gain domains. With these characteristics in mind, it may be concluded that both the disposition investor and the speculator possess characteristics of the rational investor and the contrarian. A disposition investor learns the behaviour of a rational investor over gain domains but imitates the contrarian over loss domains. The speculator behaves thoroughly oppositely. Since the rational investor and the contrarian have linear form of behaviours, 

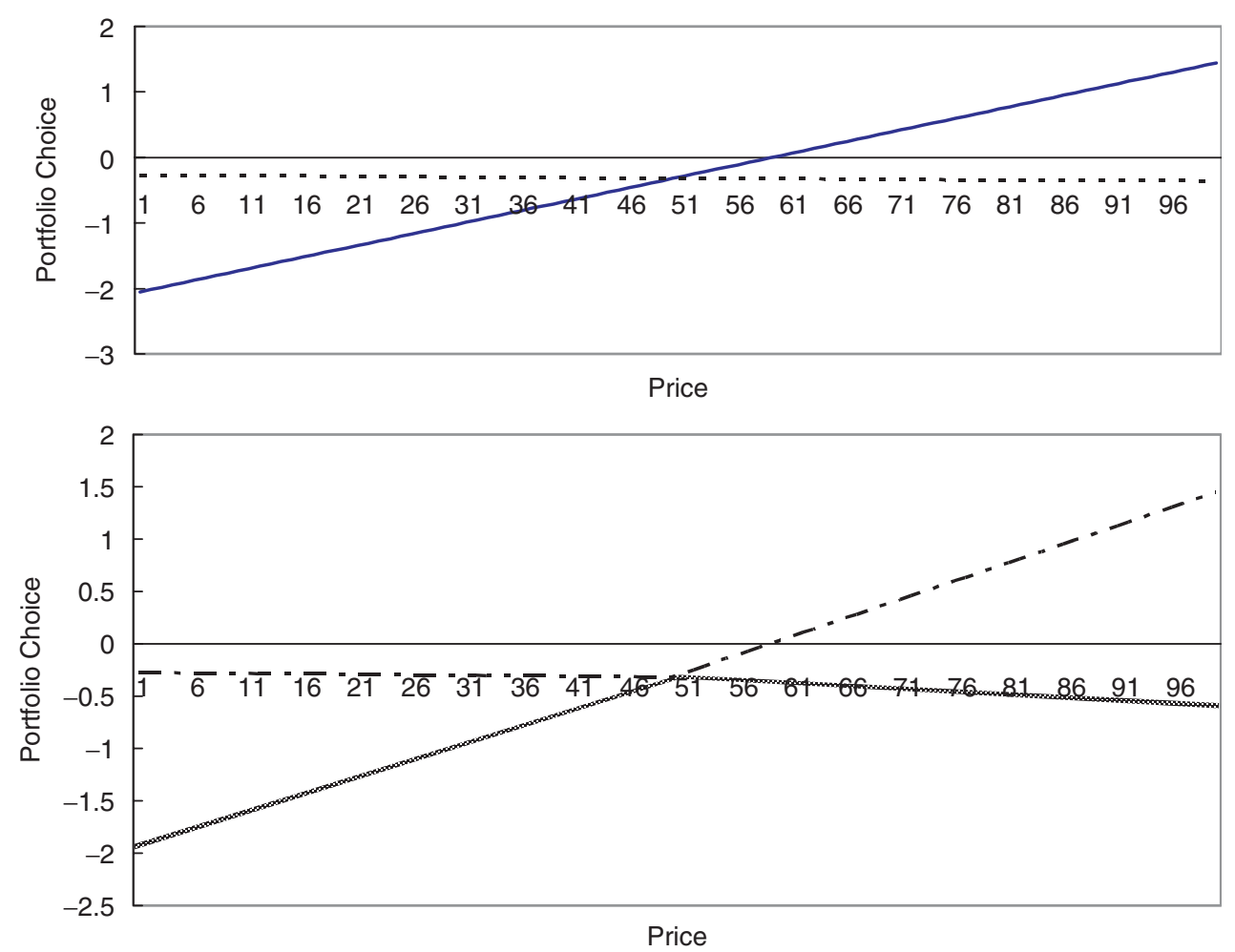

Fig. 3. Four specific investment behaviours: Both the rational investor and the contrarian have the investment behaviour of linear forms but the disposition investor and the speculator have the kinked forms. The disposition investor behaves like the rational investor over gain domains but behaves like the contrarian over loss domains. Thus she could be viewed as the compound of them. The speculator is just opposite to her. Therefore the disposition investor and the speculator generate different kinked portfolio curves: (-) rational investor, (- - - -) contrarian, $(---)$ disposition investor, $(-)$ speculator.

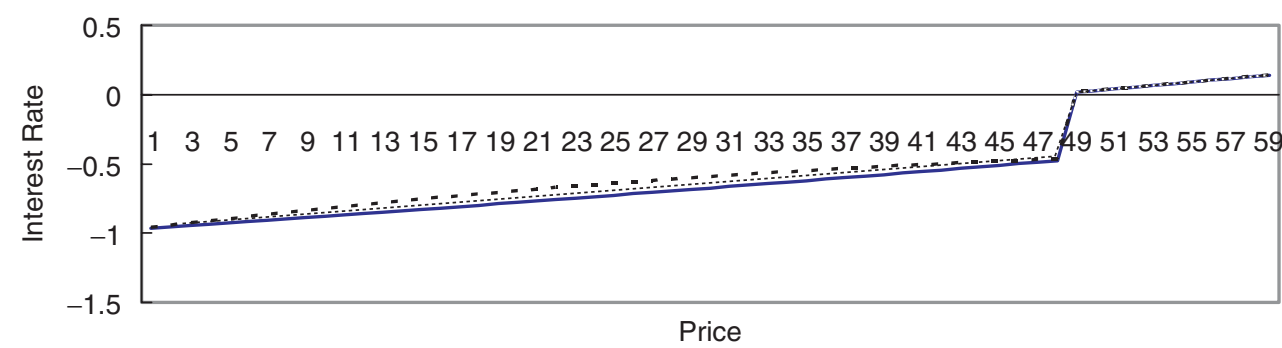

Fig. 4. The market interest rate in the heterogeneous economy: Higher stock prices crowd out the bond market capital and absorb the hot money into the stock market. It carries the falling of the bond price and raises the market interest rate. However, when price drops, greater magnitude of disposition effect deteriorates the free capital mobility from the stock market to the bond market and thus mitigates the dropping of the market interest rate: $(-)$ lamda $1=0,(\cdots \cdots)$ lambda $1=0.6,(-----)$ lambda $1=1.2$.

the disposition investor and the speculator imitate characteristics from them respectively, and thus generate the different kinked portfolio curves. This phenomenon is illustrated in Fig. 3.

\section{Market interest rate}

The relationship between the disposition effect and the market interest rate in the heterogeneous economy is calibrated in Fig. 4. It is intuitive that higher stock prices sponge market hot money from the bond market to the stock market and therefore raise the market interest rate. However, when price drop, greater magnitude of disposition effect reduces the capital, mobility from the stock market to the bond market and thus mitigates the dropping of the market interest rate. This phenomenon is plotted in Fig. 4. 


\section{Conclusion}

The high portfolio choice and the disposition effect when the stock price is low is successfully modelled. Also, it is found that higher cognitive reference price level, greater magnitude of irrational belief in mean reversion and less risk aversion attitude all strengthen the disposition effect. In addition, four specific investment behaviours are sorted based on whether irrational belief in mean reversion works in this model. Both the disposition investor and the speculator with the kinked behaviours could be viewed as the compounds of the rational investor and the contrarian. Finally, the market clearing condition is used to solve for the equilibrium market interest rate. Disposition effect intervenes with the free flow of capital from the stock market to the bond market while price falls, and thus mitigates the dropping of the market interest rate.

\section{References}

Affuso, L. (2002) An empirical study on contractual heterogeneity within the firm: the 'vertical integration-franchise contracts' mix, Applied Economics, 34, 931-44.

Andreassen, P. (1988) Explaining the price-volume relationship: the difference between price changes and changing prices, Organizational Behaviour and Human Decision Processes, 41, 371-89.

Arak, M. and Taylor, D. (1996) Optimal trading with mean-reverting prices: switching between foreign stocks and closed-end country funds, Applied Economics, 28, 1067-74.

Badrinath, S. and Lewellen, W. (1991) Evidence on taxmotivated securities trading behaviour, Journal of Finance, 46, 369-82.

Barber, B. and Odean, T. (2002) All that glitters: the effect of attention and news on the buying behaviour of individual and institutional investors, Working paper, UC Berkeley.

Barber, B., Odean, T. and Zhu, N. (2003) Systematic noise, Working paper, UC Davis.

Barberis, N. and Thaler, R. (2002) A survey of behavioural finance, Working Paper, University of Chicago.

Campbell, J. Y. (2000) Asset pricing at the millennium, Journal of Finance, 55, 1515-67.

Campbell, J. Y. and Viceira, L. M. (2002) Strategic Asset Allocation, Oxford University Press, NY.

Chang, J. R. and Hung, M. W. (2002) Intertemporal hedge for inflation risk, Applied Economics Letters, 9(4), 241-43.

Constantinides, G. (1984) Optimal stock trading with personal taxes: implications for prices and the abnormal January returns, Journal of Financial Economics, 13, 65-69.
Coval, J. and Shumway, T. (2000) De behavioral biases affect prices, Working paper, University of Michigan.

Czarnitzk, D. and Stadtmann, G. (2005) The disposition effect-empirical evidence on purchases of investor maganizes, Applied Financial Economics Letters, 1, 47-51.

Detemple, J. and Murthy, S. (1997) Equilibrium asset prices and no-arbitrage with portfolio constraints, Review of Financial Studies, 10, 1133-74.

Dumas, B. (1989) Two-person dynamic equilibrium in the capital market, Review of Financial Studies, 2, 157-88.

Dyl, E. (1977) Capital gains taxation and the year-end stock market behavior, Journal of Finance, 32, 165-75.

Genesove, D. and Mayer, C. (2001) Loss aversion and seller behaviour: evidence from the housing market, Quarterly Journal of Economics, 116, 1233-60.

Grinblatt, M. and Han, B. (2001) The disposition effect and momentum, Working paper, UCLA.

Grinblatt, M. and Keloharju, M. (2001) What makes investor trade, Journal of Finance, 56, 589-616.

Harris, L. (1988) Discussion of predicting contemporary volume with historic volume at differential price levels: evidence supporting the disposition effect, Journal of Finance, 43, 698-99.

Holman, J. A. and Graves, P. E. (2002) Implications of consumer heterogeneity in time-series estimates of US money demand, Applied Economics, 34, 659-65.

Kahneman, D. and Tversky, A. (1979) Prospect theory: an analysis of decision under risk, Econometrica, 46, $171-85$.

Kogan, L. and Uppal, R. (2000) Risk aversion and optimal portfolio policies in partial and general equilibrium economies, Working paper, MIT.

Kogan, L. and Uppal, R. (2002) Asset prices in a heterogeneous-agent economy with portfolio constraints, Working paper, MIT.

Lakonishok, J. and Smidt, S. (1986) Volume for winners and losers: taxation and other motives for stock trading, Journal of Finance, 41, 951-74.

Locke, P. R. and Mann, S. C. (1999) Do professional traders exhibit loss realization aversion, manuscript, Division of Economic Analysis, Commodity Futures Trading Commission and Neeley School of Business.

Odean, T. (1998) Are investors reluctant to realize their losses, Journal of Finance, 53, 1775-98.

Odean, T. (1999) Do investors trade too much?, American Economic Review, 89, 1279-98.

Shapira, Z. and Venezia, I. (2001) Patterns of behavior of professionally managed and independent investors, Journal of Banking and Finance, 25, 1573-87.

Shefrin, H. and Statman, M. (1985) The disposition to sell winners too early and ride losers too long: Theory and evidence, Journal of Finance, 40, 777-90.

Vasicek, O. (1977) An equilibrium characterization of the term structure, Journal of Financial Economics, 5, $177-88$.

Wang, J. (1996) The term structure of interest rates in a pure exchange economy with heterogeneous investors, Journal of Financial Economics, 41, 75-110.

Wirjanto, T. S. (2004) Exploring consumption-based asset pricing model with stochastic-trend forcing process, Applied Economics, 36, 1591-97. 
Copyright of Applied Economics is the property of Routledge and its content may not be copied or emailed to multiple sites or posted to a listserv without the copyright holder's express written permission. However, users may print, download, or email articles for individual use. 